\title{
Cross-Scale Responses of Biodiversity to Hurricane and Anthropogenic Disturbance in a Tropical Forest
}

\author{
Michael R. Willig, ${ }^{1, *}$ Christopher P. Bloch, ${ }^{2,3}$ Nicholas Brokaw, ${ }^{4}$ \\ Christopher Higgins, ${ }^{5}$ Jill Thompson, ${ }^{4}$ and Craig R. Zimmermann ${ }^{2}$
} ${ }^{1}$ Center for Environmental Sciences and Engineering and Department of Ecology and Evolutionary Biology, University of Connecticut,
Storrs, Connecticut 06269, USA; ${ }^{2}$ Ecology Program, Department of Biological Sciences, Texas Tech University, Lubbock, Texas 79409,
USA; ${ }^{3}$ Department of Biological Sciences, Bridgewater State College, Bridgewater, Massachusetts 02325, USA; ${ }^{4}$ Institute for Tropical
Ecosystem Studies, University of Puerto Rico, P.O. Box 21910, San Juan, Puerto Rico 00931-1910, USA; ${ }^{5}$ Department of Biological Sciences, Tarleton State University, Stephenville, Texas 76402-0100, USA

\begin{abstract}
In studies of biodiversity, considerations of scale - the spatial or temporal domain to which data provide inference-are important because of the non-arithmetic manner in which species richness increases with area (and total abundance) and because fine-scale mechanisms (for example, recruitment, growth, and mortality of species) can interact with broad scale patterns (for example, habitat patch configuration) to influence dynamics in space and time. The key to understanding these dynamics is to consider patterns of environmental heterogeneity, including patterns produced by natural and anthropogenic disturbance. We studied how spatial variation in three aspects of biodiversity of terrestrial gastropods (species richness, species diversity, and nestedness) on the 16-ha Luquillo Forest Dynamics Plot (LFDP) in a tropical forest of Puerto Rico was affected by disturbance caused by Hurricanes Hugo and Georges, as well as by patterns of historic land use. Hurricane-induced changes in spatial organization of species richness differed from those for species diversity. The gamma components of species richness changed after the hurricanes and were significantly different between Hurricanes
\end{abstract}

Received 1 September 2006; accepted 9 April 2007

*Corresponding author; e-mail: michael.willig@uconn.edu
Hugo and Georges. Alpha and two beta components of species richness, one related to turnover among sites within areas of similar land use and one related to variation among areas of different land use, varied randomly over time after both hurricanes. In contrast, gamma components of species diversity decreased in indistinguishable manners after both hurricanes, whereas the rates of change in the alpha component of species diversity differed between hurricanes. Beta components of diversity related to turnover among sites declined after both hurricanes in a consistent fashion. Those related to turnover among areas with different historic land uses varied stochastically. The immediate effect of hurricanes was to reduce nestedness of gastropod assemblages. Thereafter, nestedness increased during post-hurricane secondary succession, and did so in the same way, regardless of patterns of historic land use. The rates of change in degree of nestedness during secondary succession were different after each hurricane as a result of differences in the severity and extent of the hurricane-induced damage. Our analyses quantified temporal changes in the spatial organization of biodiversity of gastropod assemblages during forest recovery from hurricane-induced damage in areas that had experienced different patterns of historic human land use, and 
documented the dependence of biodiversity on spatial scale. We hypothesize that cross-scale interactions, likely those between the local demographics of species at the fine scale and the landscape configuration of patches at the broad scale, play a dominant role in affecting critical transfer processes, such as dispersal, and its interrelationship with aspects of biodiversity. Cross-scale interactions have significant implications for the conservation of biodiversity, as the greatest threats to biodiversity arise from habitat modification and fragmentation associated with disturbance arising from human activities.

Key words: biodiversity; gastropods; historic land use; nestedness; Puerto Rico; spatial heterogeneity; species diversity; species richness; succession; temporal heterogeneity; tropical forest.

\section{INTRODUCTION}

Scale, the spatial or temporal domain to which data provide inference, has become an increasingly important topic in studies that focus on aspects of biodiversity from an ecological perspective (for example, Holling 1992; Levin 1992; Peterson and others 1998; Waide and others 1999; Scheiner and others 2000; Mittelbach and others 2001; Chase and Leibold 2002; Chalcraft and others 2004; Gorresen and others 2005; Peters and Havstad 2006) and biogeographic perspective (for example, Lyons and Willig 1999, 2002; Whittaker and others 2001; Stevens and Willig 2002; Willig and others 2003; Srivastava 2005; Willig and Bloch 2006). Biodiversity at a larger spatial scale (for example, gamma diversity of a plot) is a consequence of two factors: biodiversity at a smaller spatial scale (for example, alpha diversity of sites within a plot) and the differences in biodiversity among sites within the plot (for example, turnover or beta diversity of the plot). Explicit considerations of scale in studies of biodiversity are important because the form and parameterization of relationships between aspects of biodiversity (for example, species richness) and environmental factors (for example, productivity) can be quite different (for example, positive linear, negative linear, or modal) depending on the size of sampling units and the extent of the larger system within which they are dispersed (for example, Scheiner and others 2000; Willig and others 2003). Two general factors contribute to this phenomenon. The first deals with the way in which aspects of biodiversity increase with area. The second concerns dynamics associated with cross-scale interactions.

Biodiversity is a multidimensional attribute whose components (for example, species richness, evenness, and diversity) change in space in markedly non-arithmetic manners (Levin 1992; Allen and Hoekstra 1993). Two contrasting examples illustrate this point. Consider a plot comprising four smaller sites. The aboveground biomass on each of the sites is $2,4,6$, and $8 \mathrm{~kg}$; the species richness of the same sites (alpha level) is 2, 4, 6, and 8, respectively. The total aboveground biomass of the plot is $20 \mathrm{~kg}$ (that is, $2+4+6+8$ ), whereas the total species richness of the plot (gamma level) is unknown, although it could assume a value from 8 to 20 species, depending on the differences among smaller sites in species composition (beta level). These examples demonstrate that the effect of spatial scale depends on the characteristics of particular ecological attributes, and that scaling from small to large areas for species richness is more complicated than scaling for other attributes, such as biomass. Clearly, ecological attributes may change with scale in different manners (either the form or parameterization of the relationships differ), and consequently their relationship with each other may change with scale as well, resulting in scale dependence. Such scale-dependent effects have caused considerable controversy in investigations concerning environmental gradients, such as that chronicled in the debate about the relationship between diversity and productivity (see Huston 1994, 1997; Lawton 1994; Wardle and others 1997; Lawton and others 1998; Waide and others 1999; Mittelbach and others 2001).

\section{Species Richness, Habitat Heterogeneity, and Area}

Patterns of environmental heterogeneity and the factors that influence it are key to understanding the way in which ecological attributes, notably those that involve species identity, change with scale. Ecology's oldest law is that species richness increases with area (von Humboldt 1807). Although considerable controversy still surrounds the appropriate model for describing the form of the relationship (Gray and others 2004a, b; Scheiner $2003,2004)$, the power function is the most commonly used scaling function for area $\left(S=C A^{z}\right.$, wherein $S$ represents species richness, A represents area, and $C$ and $z$ are fit constants from least squares analysis of the log-log relationship or from non-linear analogs (Arrhenius 1921, 1923a, b)). 
Uncertainty regarding the form of the scaling relationship arises because increases in area generally are accompanied by increases in habitat diversity and in number of individuals, each of which may increase species richness in different ways. The manner in which aspects of habitat heterogeneity change with area depends on the particular geographic region in which the samples are accumulated, the spatial dynamics of the disturbance regime (for example, Falk and others 2007), and the abundance distribution of the species pool across the cumulative set of habitats in the region. Consequently, general models for speciesarea relationships, which must be responsive to both habitat heterogeneity and the abundance distribution of a region's species pool, are essentially phenomenological in nature.

\section{Spatial Organization}

At the community or assemblage level, several patterns of spatial organization have been identified, including checkerboards (Diamond 1975), Clementsian gradients (Clements 1916), Gleasonian gradients (Gleason 1926), random distributions (Simberloff 1983), and nestedness (Patterson and Atmar 1986). Of these, nestedness-the extent to which taxa found in species-poor areas are a proper subset of those in species-rich areas-is among the most frequently studied patterns. Although traditionally viewed as a large scale, static pattern derived from biogeographic processes, such as extinction and colonization, recent work has applied the nestedness concept to local assemblages for understanding aspects of spatial and temporal dynamics (Kaufman and others 2000; Leibold and Mikkelson 2002; Norton and others 2004; Azeria and others 2006). Indeed, nestedness may vary with scale because different mechanisms drive the pattern at each scale (Summerville and others 2002; Sfenthourakis and others 2004). Moreover, temporal changes in nestedness may be profound in assemblages that periodically experience largescale disturbance, such as hurricanes, because of the drastic reorganization of habitat patches within local landscapes (Bloch and others 2007).

\section{Cross-Scale Interactions}

Cross-scale interactions, especially those generated by natural or anthropogenic disturbances (that is, environmental drivers), play a critical role in ecosystems by effecting dynamics in time and space (Peters and Havstad 2006). Cross-scale interactions refer to processes at one spatial or temporal scale that interact with processes at another scale to result in nonlinear dynamics or thresholds. These interactions alter the relationships between pattern and process across scales such that fine-scale processes can influence a broad spatial extent or a long time period, or broad-scale drivers can interact with fine-scale processes to determine system dynamics (Peters and others 2006). Disturbances affect the life history and demographic parameters of species at fine spatial scales by altering the local abiotic, biotic, or structural environment (Figure 1A). Moreover, the differences among these local patches in environmental characteristics, as well as their spatial configuration, affect the dispersal of individuals to and from patches (that is, the transfer process), altering the effective degree of connectedness among patches in a species-specific manner, coincident with niche characteristics of species. As secondary succession advances, the biotic, abiotic, and structural characteristics of local sites change as a result of the interaction between fine-scale processes and transfer processes among sites. Changes in environmental characteristics at a local scale alter the nature and configuration of patches at the broad scale of the landscape, thereby creating a cascade of cross-scale interactions (Figure 1B). Consequently, cross-scale interactions have the potential to significantly mold spatial patterns of biodiversity and likely do so in complex ways, especially during post-hurricane secondary succession.

\section{Context}

As a consequence of its high species richness and endemism (Woods 1989; Woods and Sergile 2001), the Caribbean Basin has been designated as a global hotspot of terrestrial biodiversity (Myers and others 2000; Myers 2001). Moreover, the region is characterized by high cyclonic activity (Landsea and others 1999) and rapid changes in human land use (for example, López and others 2001), so that the structure and function of its ecosystems are molded by hurricanes and humans (Tanner and others 1991; Grau and others 2003). Because the number and intensity of tropical storms likely will increase in the region (Goldenberg and others 2001; Webster and others 2005), and land-use change continues unabated, it is important to understand the ways in which such disturbances alter biotas, especially in light of their role in mediating ecosystem function and resulting services to humans. In this paper, we illustrate the complex ways in which disturbance-generated heterogeneity from hurricanes and historic human land use affected spatial aspects and temporal trajectories of biodi- 


\section{A Spatially implicit conceptual model of disturbance and response at fine spatial scales}

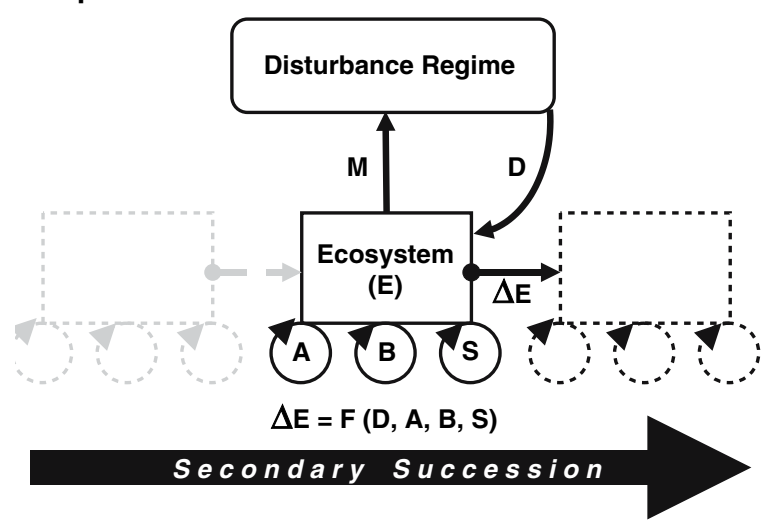

B Spatially explicit framework with
cross-scale interactions
DISTURBANCE

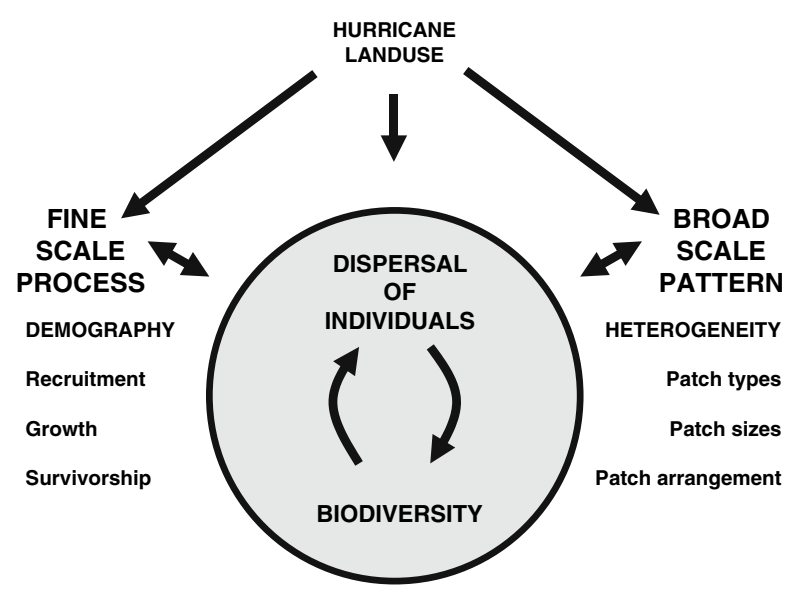

versity in a tropical forest in Puerto Rico. We focus on terrestrial gastropods because they are an abundant group of keystone heterotrophs for which data on the spatial and temporal dynamics of different populations are available at multiple spatial scales.

\section{Materials AND Methods}

This study was conducted in the Luquillo Experimental Forest in the Luquillo Mountains of northeastern Puerto Rico. Spatial and temporal heterogeneity in Luquillo Experimental Forest arises from a number of interacting phenomena that operate at different scales. The geological heterogeneity of the Luquillo Mountains underlies climatological gradients (for example, temperature, precipitation) that are produced by elevational relief in mountains that rise to $1,075 \mathrm{~m}$ a.s.l.
Figure 1. Two conceptual models illustrating the interaction of environmental factors that affect variation in time and space. A At a fine scale, the conceptual model of Willig and Walker (1999) is spatially implicit, and illustrates the way in which a particular disturbance event (for example, a hurricane, D) affects the state of an ecosystem $(E)$ and subsequent successional dynamics $(\Delta E)$. In particular, a hurricane alters abiotic (A) conditions (for example, increases light penetration to forest floor), biotic (B) conditions (for example, kills trees and displaces snails), or structural (S) characteristics (for example, removes branches and leaves from trees and deposits both on the forest floor) of some portion of a landscape. These modifications of habitat subsequently alter the behavior of individuals and create different local selection regimes, thereby affecting a cascade of changes known as secondary succession. B Hurricanes directly effect broad-scale patterns of habitat heterogeneity (aspects of patchiness), in addition to fine scale demographic processes. In a spatially explicit model (Peters and Havstad 2006), the association between the dispersal of individuals of different species and patterns of biodiversity are critically dependent on cross-scale linkages between local demographic processes at the fine scale and landscape heterogeneity of patches at the broad scale.

within $5 \mathrm{~km}$ of the ocean (Brown and others 1983). This heterogeneity is further modified by a disturbance regime that includes both natural and anthropogenic agents (Pickett and Cadenas 1999). Disturbance is a major driver of ecosystem dynamics in the Luquillo Mountains, which are struck by severe hurricanes every 50-60 years on average (Scatena and Larsen 1991) and which have a well-documented history of anthropogenic land use (García-Montiel and Scatena 1994; Thompson and others 2002). Research in the Luquillo Experimental Forest provides a wealth of background information on the responses of plants, animals, and biogeochemical processes to hurricanes (for example, Walker and others 1991, 1996; Waide and Lugo 1992), as well as on the effects of historic land use (for example, Willig and others 1996; Aide and others 2000). Finally, the biota continues to respond to disturbances during the process of secondary succession, which imposes yet another level of spatial variation on an already heterogeneous landscape. More specifically, any particular element (for example, hurricane, tree fall, forestry practice) or interaction of elements of a disturbance regime affects a geographically explicit portion of a landscape by altering the biotic, abiotic, or structural characteristics of the system, with consequences to both state variables and fluxes (Figure 1A; Willig and Walker 1999). Moreover, 


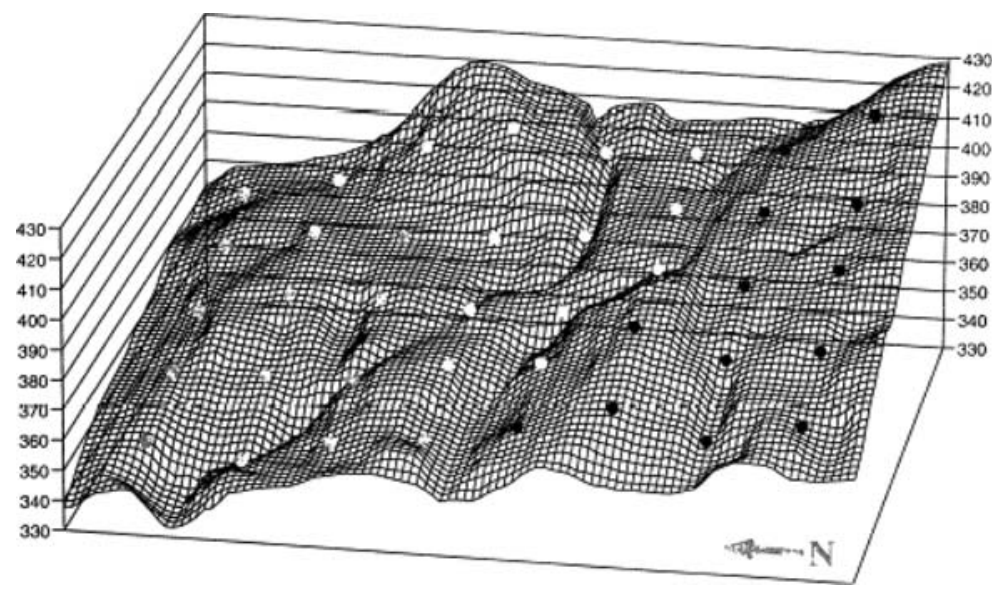

Figure 2. Topography of the Luquillo Forest Dynamics Plot (LFDP) at El Verde, Puerto Rico, showing the location of forty $3-\mathrm{m}$ radius sites in which gastropods were censused. Vertical axis is meters above sea level. Canopy cover classes (white circles cover classes 1 and 2, grey circles cover class 3, and black circles, cover class 4) reflect different types and intensities of historic land use on the LFDP, based on analysis of aerial photographs taken in 1936. the effects of the disturbance are mediated by the state of the system at the time of the disturbance. In synergy, the underlying heterogeneity of the environment, disturbance regime including anthropogenic and natural agents, and the state of the system at the time of disturbance determine the subsequent rates and directions of change in biodiversity and influence the patterns of community organization in space and time.

\section{Field Site}

The study took place on the Luquillo Forest Dynamics Plot [LFDP (SW corner at $18^{\circ} 20^{\prime} \mathrm{N}$, $65^{\circ} 49^{\prime} \mathrm{W}$; c. $330-400 \mathrm{~m}$ a.s.l.)] in the Luquillo Experimental Forest (Waide and Reagan 1996). Rainfall averages 3,500 $\mathrm{mm} \mathrm{year}^{-1}$, with no month experiencing less than $200 \mathrm{~mm}$ of precipitation. Nonetheless, as a result of the variation in the probability of daily rainfall a modest "drier season" extends from January to April, and a "wetter season" from May to December. The forest is typical of the tabonuco forest zone (below $600 \mathrm{~m}$ elevation) in the Luquillo Mountains (Brown and others 1983), and is classified as subtropical wet in the Holdridge life zone system (Ewel and Whitmore 1973). The LFDP comprises 16 ha of varied terrain and soils (Figure 2; Thompson and others 2002, 2004). Like the rest of the forest, the LFDP was disturbed by human activities of different intensities prior to its purchase by US Forest Service in 1934, including limited selective logging, which continued in a few small areas until the 1950s (Thompson and others 2002). Based on percent canopy cover evident in aerial photographs taken in 1936, US Forest Service records, and other sources, the LFDP can be subdivided into four canopy cover classes (Thompson and others 2002). For this study, canopy cover classes 1 and 2 were combined to increase sample size, resulting in three areas of historic land use (Figure 2). Cover classes 1 and $2(0-49 \%$ canopy cover in 1936) experienced the most intensive logging and agriculture prior to 1934. Cover class $3(50-80 \%$ canopy cover in 1936) was used for shade-coffee cultivation and other small scale mixed agriculture before 1934. Cover class 4 (80-100\% canopy cover in 1936) was lightly and selectively logged up to the 1950s. After purchase, the forest was allowed to revert to closed canopy forest. Nevertheless, current differences in tree species composition as well as functional diversity of microbes, continue to reflect the history of human activity (Willig and others 1996; Thompson and others 2002). In 1989 and 1998, the LFDP was struck by major natural disturbances, Hurricane Hugo (category 4 storm) and Hurricane Georges (category 3 storm), respectively. The spatial distribution of damage to the forest from each hurricane was influenced by the tree species composition of local sites, as tree species have different susceptibilities to types of damage (Zimmerman and others 1994).

\section{Terrestrial Gastropods}

Terrestrial gastropods are a species-rich, conspicuous, and abundant group of animals in tabonuco forest of Puerto Rico (34 species overall; 18 on the LFDP, Garrison and Willig 1996; Willig and others 1998). Because of their numbers, biomass, and varied roles as litter feeders, herbivores, and carnivores, terrestrial gastropods may act as keystone heterotrophs in many terrestrial systems (Mason 1970; Purchon 1977). These gastropods respond to both historic land use patterns and natural disturbances, such as hurricanes and tree fall gaps (Willig and Camilo 1991; Alvarez and Willig 1993; Secrest and others 1996; Willig and others 1998; Bloch and Willig 2006). 
From 1991 through 2004, data on gastropod populations were collected in a standardized fashion from each of 40 circular sites $(3 \mathrm{~m}$ radius by $3 \mathrm{~m}$ vertical height) arranged in a rectilinear grid, with $60 \mathrm{~m}$ inter-site spacing in the LFDP (Figure 2; Willig and others 1998; Bloch and Willig 2006). Each of the 40 sites was classified according to its location with respect to the 1936 cover class designations that reflect historic land use (see above), with 13 sites in cover classes 1 and 2 as a group, and 14 and 13 sites in cover classes 3 and 4, respectively. Sampling was conducted during two seasons each year: once in March, during the drier season, and again from June to August, during the wetter season.

\section{Analytical Methods}

Biodiversity of gastropods at the sites was estimated by species richness ( $S$, the number of sampled species) and Shannon's index $\left(H^{\prime}\right)$ of diversity (Magurran 1988). The latter incorporates aspects of richness and evenness, and may be defined as

$$
\mathrm{H}^{\prime}=-\sum_{i=1}^{5} p_{\mathrm{i}}\left(\ln p_{\mathrm{i}}\right)
$$

where $p_{\mathrm{i}}$ equals the proportional abundance of the $\mathrm{i}^{\text {th }}$ species, given as the ratio of the number of sampled individuals of species $\mathrm{i}\left(n_{\mathrm{i}}\right)$ to the total number of sampled individuals $(N)$ of all species (that is, $\left.p_{\mathrm{i}}=n_{\mathrm{i}} / N\right)$. Evenness $(E)$ reflects the extent to which all $S$ species exhibit the same abundance, and may be measured as the ratio of observed diversity to maximal diversity

$$
E=H^{\prime} / H_{\max }^{\prime}
$$

where $H_{\text {max }}^{\prime}$ is calculated when the proportional abundances of all species are the same (for all $i$, $\left.p_{\mathrm{i}}=1 / S\right)$.

For each sample of the gastropod assemblage in the wetter season, an estimate of biodiversity (that is, the biodiversity of terrestrial gastropods on the entire LFDP) based on species richness and Shannon's index (hereafter, $S_{\gamma}$ and $H^{\prime}{ }_{\gamma}$, respectively) was partitioned with respect to $\alpha$ and $\beta$ components using program PARTITION (Crist and others 2003). For each measure of biodiversity at the $\gamma$ level, three subcomponents were recognized: $\alpha$ biodiversity, representing the average biodiversity of sampling sites $\left(S_{\alpha}\right.$ or $\left.H_{\alpha}^{\prime}\right), \beta$ biodiversity among sites $\left(S_{\text {sites }}\right.$ or $H^{\prime}$ sites), and $\beta$ biodiversity among historic cover classes $\left(S_{\mathrm{Cc}}\right.$ or $\left.H^{\prime}{ }_{\mathrm{cc}}\right)$. Importantly, $S_{\mathrm{cc}}$ and $H_{\mathrm{cc}}^{\prime}$ each reflect two contributory factors: effects related to differences in environmental conditions or disturbance history among cover classes, as well as differences related to distance effects, which are confounded and not distinguishable in subsequent analyses. In addition, the spatial structure of gastropod assemblages was characterized using $\mathrm{PN}_{\mathrm{C}}$ (Wright and others 1998), a standardization of the $\mathrm{N}_{\mathrm{c}}$ metric of nestedness. It represents the sum of all conditional probabilities that a species will be present at a site, given its presence at more depauperate sites (that is, the number of times a species presence at one site correctly predicts its presence at equally rich or more rich sites, summed for all species and all sites; Wright and Reeves 1992). More specifically, nestedness $\left(\mathrm{N}_{\mathrm{c}}\right)$ is given by

$$
\mathrm{N}_{\mathrm{c}}=\sum_{i=1}^{K-1} \sum_{m=i+1}^{K} \sum_{j=1}^{S} X_{i j} X_{m j}
$$

where $K$ is the number of sites, $S$ is the number of species, and $X_{i j}$ is the entry for species $j$ at site $i$ (a 1 if present, a 0 if absent). The standardized measure of $\mathrm{N}_{\mathrm{c}}$ (that is, $\mathrm{PN}_{\mathrm{c}}$ ) is based on the observed value of $\mathrm{N}_{\mathrm{C}}$, the expected value of $\mathrm{N}_{\mathrm{C}}$ (derived from a null model), and the maximum value of $\mathrm{N}_{\mathrm{c}}$ via the relationship:

$$
\underset{\left.\left(N_{c}\right)\right\}^{-1}}{P_{C}}=\left\{N_{c}-\text { expected }\left(N_{c}\right)\right\}\left\{\max \left(N_{c}\right)-\right.\text { expected }
$$

whose rationale is discussed fully in Wright and Reeves (1992).

Via SPSS (1990a, b), repeated measures analysis of covariance (ANCOVA) was used to evaluate effects of natural disturbance on biodiversity based on each measure of biodiversity ( $S$ and $H^{\prime}$ ) at each spatial scale $\left(\alpha, \beta_{\text {sites }}, \beta_{\mathrm{CC}}, \gamma\right)$. In all cases, the within-subjects factor was hurricane, which identified whether a sample was collected in the time period following Hurricane Hugo and before Hurricane Georges (1991-1998), or that following Hurricane Georges (1998-2004). The covariate was time since disturbance, measured in years. Because of the paired nature of the design, data for a particular year were included only if data existed for a particular value of the covariate (time since disturbance) for both hurricanes. Because sample size and degrees of freedom are small and this is a heuristic study, we chose to reject the null hypothesis at $\alpha=0.10$.

Because biodiversity at the gamma scale is equal to the sum of biodiversity at the alpha scale, beta scale among plots, and beta scale among cover classes, statistical analyses for all four components of a particular index (that is, richness or diversity) are not independent, leading to elevated likeli- 
hoods of rejecting the null hypothesis when it is true (Type I error rates). Rather than conducting more complicated multivariate analogues of the repeated measures ANCOVAs, or conducting a repeated measures ANCOVA on each of a number of independent measures of biodiversity derived from a data-reduction technique such as Principal Components Analysis or Multidimensional Scaling-each of which requires adherence to a number of additional statistical assumptions-we chose to apply Bonferroni sequential adjustments (Rice 1989) to broadly assess multivariate significance and to protect against elevated Type I error rates with respect to each index of biodiversity. As such, significant effects prior to Bonferroni adjustment for alpha, beta, or gamma components of any aspect of biodiversity (that is, richness or diversity) are considered to be weak if the suite of four metrics does not yield overall significance after correction by the Bonferroni technique [considered by some (Hurlbert 2003; Moran 2003) to be quite conservative].

Repeated measures ANCOVA (SPSS 1990a, b) was used to evaluate effects of patterns of historic land use and natural hurricane disturbance on nestedness of gastropod assemblages at two hierarchical spatial scales: the entire LFDP and separately for each of the three canopy cover classes. In both cases, the within-subjects factor was hurricane (Hugo versus Georges), and the covariate was time since hurricane disturbance. For the analysis at the scale of the entire LFDP, a between-subjects factor was included to identify regions of historic land use defined by canopy cover class (CC) within which the nestedness of sites was assessed over time. Because of the paired nature of the sampling design, we only included data if they existed for a comparable time, in seasons, after both hurricanes (that is, the covariate). Again, we rejected the null hypothesis at $\alpha=0.10$.

\section{Simulation Analyses}

The possible effects of hurricane-induced mortality on changes in the degree of nestedness were assessed using two different models, one simulating density-independent mortality and the other simulating density-dependent mortality. Densityindependent mortality was modeled separately for each site. A uniform random number between 0 and 1 was generated for each species. If the random number was less than the extirpation threshold, which systematically varied from 0.1 to 0.9 in increments of 0.1 , then that species was removed from the site and considered to be locally extinct.
Density-dependent mortality was modeled in a parallel fashion, except that a uniform random number between 0 and 1 was generated for each individual. If the random number was less than the extirpation threshold, which systematically varied from 0.1 to 0.9 in increments of 0.1 , then that individual was removed from the site. Only when all of the individuals of a particular species had been removed from a site was the species locally extinct. Thus, the likelihood of extirpation at a site decreased with increased abundance at that site. Each of the two models was executed based on sitespecific data for snail abundances prior to Hurricane Georges. The results of each iteration of the simulation produced a binary (presence or absence) matrix that was used to assess nestedness, as estimated by the $\mathrm{N}_{\mathrm{c}}$ index in its standardized form $\left(\mathrm{PN}_{\mathrm{c}}\right)$, thereby removing the correlation between the rank of the data matrix and the magnitude of the index (Wright and Reeves 1992; Wright and others 1998). Statistical significance was assessed from 1,000 interations of randomized data generated with the RANDOMl null model. We repeated this entire process 100 times to estimate mean nestedness values for each model. Although mortality may differ among species and be related to site-specific variation in the intensity of disturbance, among other things, those aspects of hurricane effects were not modeled here.

\section{Results And Discussion}

\section{Spatial and Temporal Variation in Biodiversity}

Temporal changes in biodiversity of gastropods after hurricane-induced disturbance were scaledependent albeit weak, regardless of whether biodiversity was expressed as $S$ or $H^{\prime}$ (Table 1). $S$ exhibited a discernable trend over time only at the largest spatial scale $\left(S_{\gamma}\right)$. However, the post-disturbance trajectory of $S_{\gamma}$ depended on hurricane identity, as the direction of post-hurricane change differed between the two hurricanes [Figure 3A; Table 1, significant hurricane by time since disturbance interaction $(P=0.052)]$. Although $H_{\gamma}^{\prime}$ declined over time following disturbance in a consistent manner, regardless of hurricane identity, this response was not reflected by all of its spatial components (Figure 4). In particular, no response was observed for $H_{\beta c c}^{\prime}$ (Figure 4D), and $H_{\alpha}^{\prime}$ declined more slowly following Hurricane Georges than it did following Hurricane Hugo [Figure 4B; Table 1, significant hurricane by time since disturbance interaction $(P=0.091)]$. 
Table 1. Results of Repeated Measures ANCOVAs Evaluating Effects of Disturbance by Hurricanes on Biodiversity of Gastropod Assemblages including Spatial Components of Species Richness and Diversity

\begin{tabular}{|c|c|c|c|c|c|c|c|c|c|}
\hline \multirow[b]{2}{*}{ Source } & \multirow[b]{2}{*}{$d f$} & \multicolumn{4}{|c|}{ Species richness $(S)$} & \multicolumn{4}{|c|}{ Shannon diversity $\left(H^{\prime}\right)$} \\
\hline & & $\alpha$ & $\beta_{\text {sites }}$ & $\beta_{\mathrm{cc}}$ & $\gamma$ & $\alpha$ & $\beta_{\text {sites }}$ & $\beta_{\mathrm{cc}}$ & $\gamma$ \\
\hline \multicolumn{10}{|l|}{ Within subjects factors } \\
\hline Hurricane & 1,3 & 0.100 & 0.635 & 0.112 & 0.066 & 0.059 & 0.732 & 0.169 & 0.192 \\
\hline Hurricane $\times$ time since disturbance & 1,3 & 0.158 & 0.430 & 0.116 & 0.052 & 0.091 & 0.452 & 0.144 & 0.180 \\
\hline \multicolumn{10}{|l|}{ Between subjects factors } \\
\hline Time since disturbance & 1,3 & 0.396 & 0.119 & 0.487 & 0.826 & 0.145 & 0.007 & 0.153 & 0.012 \\
\hline \multicolumn{10}{|c|}{$\begin{array}{l}\text { Spatial aspects reflect } \alpha \text { - and } \beta \text {-components, both among areas characterized by different anthropogenic disturbance histories as reflected in historic cover classes ( } \beta_{c c} \text { and among } \\
\text { sites }\left(\beta_{\text {sites }}\right) \text {. "hurricane" identifies whether a sample came from the time period following Hurricane Hugo or Hurricane Georges. } \\
\text { The factor "hore } \\
\text { The covariate measures the number of years following disturbance. Significant results } \alpha=0.10 \text { ) are bold. After adjustment by the Bonferroni technique, none of the results for } \\
\text { species richness were significant, and only the effect of time since disturbance was significant for diversity; this suggests that within subjects factors had only weak effects. }\end{array}$} \\
\hline
\end{tabular}

Temporal changes in biodiversity were more pronounced when differential abundances of species were considered (Shannon diversity) than when only the presence or absence of species (richness) defined the index of biodiversity. This probably results from species-specific patterns that typify the numerical responses of gastropod species to disturbances such as treefall gaps (Alvarez and Willig 1993) or hurricanes (Bloch and Willig 2006). In fact, the post-hurricane decrease in $H^{\prime}{ }_{\gamma}$ over time was not associated consistently with a decrease in $S$, and must therefore have been a function of decreasing species evenness, a metric that is sensitive to the differential abundances of species. The pattern resulted primarily from increasing numerical dominance of a single species, Nenia tridens, which generally was lowest in density soon after a hurricane, then increased, at times, to over $50 \%$ of total gastropod abundance (Bloch and Willig 2006). Nevertheless, increases in density of $N$. tridens had no obvious negative effects on densities of other species or on species richness (Bloch and Willig, unpublished data).

Decreasing $\beta$-diversity among sites reflected increasing similarity in species-abundance distributions among sites within cover classes (Figure 4C), but not increasing similarity in speciesabundance distributions among these areas (Figure 4D). Although $\beta$-diversity among areas of different historic land use remained consistently low, persistent habitat differences among these areas (see Willig and others 1996; Bloch and Weiss 2002; Thompson and others 2002) may have prevented continued convergence of gastropod abundance distributions. Thus, environmental heterogeneity derived from anthropogenic land-use history generated increased variability in diversity and composition of gastropod assemblages, whereas differences in characteristics of subsequent natural disturbances drove the direction and rate of successional changes.

\section{Nestedness of Gastropod Assemblages}

Although the immediate effect of hurricane-induced disturbance was to decrease nestedness of gastropods in the LFDP, during subsequent secondary succession, nestedness generally increased in magnitude (Figure 5). The rate of increase was greater after Hurricane Hugo than after Hurricane Georges [Table 2, significant hurricane by time since disturbance interaction $(P=0.001)]$. Also, the magnitude of nestedness differed among spatial domains of the LFDP as defined by canopy cover class in 1936 (Table 2), and these differences in nestedness of gastropods were consistent during successional responses to both hurricanes [Table 2, non-significant hurricane by canopy cover class interaction $(P=0.679)]$. These results indicate that assemblage structure of gastropods, as reflected in nestedness, changed over time after disturbance but that the rate and extent of change depended on the type of past disturbances and the particular recent disturbance.

We hypothesize that prior to the impact of Hurricane Hugo, when the LFDP was more homogeneous with respect to vegetation, temperature, and humidity, the snail assemblage was essentially a metacommunity, with relatively uninhibited movement of individual snails among sites. To the extent to which this is true, the metacommunity should exhibit a nested distribution of species, regardless of the underlying species abundance distribution (that is, a random placement of individuals among sites generally will yield a nested pattern of species occurrences; Higgins and others 

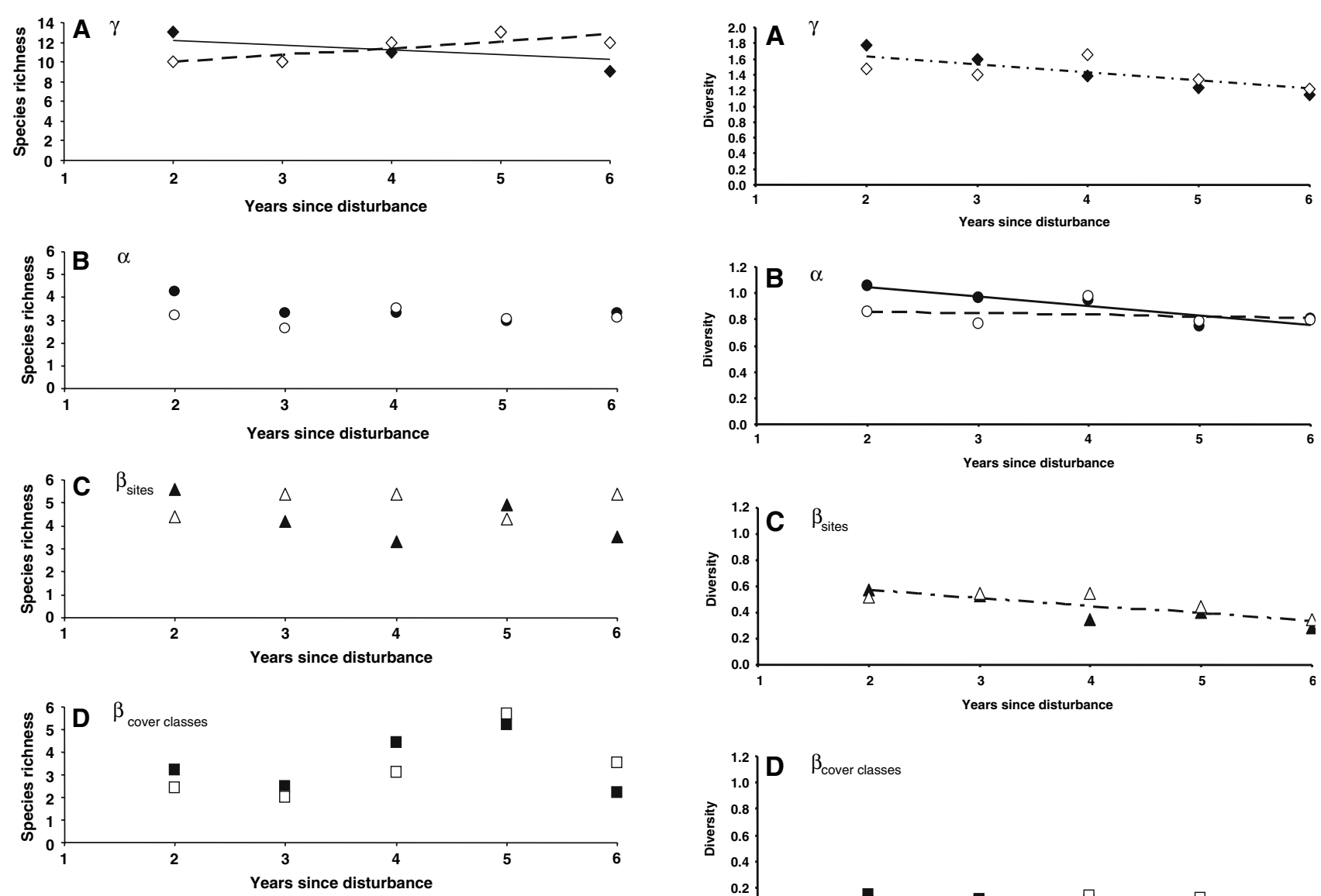

Figure 3. Long-term variation in spatial components of biodiversity as measured by species richness for terrestrial gastropods during the wet season on the Luquillo Forest Dynamics Plot, with a focus of trajectories of change after Hurricane Hugo (solid symbols and solid lines) and after Hurricane Georges (open symbols and dashed lines). Spatial scales (indicated by symbols) of species richness include: A gamma $(\gamma)$, B alpha $(\alpha)$, $\mathbf{C}$ beta among sites $\left(\beta_{\text {site }}\right)$, and D beta among cover classes $\left(\beta_{\mathrm{cc}}\right)$. The absence of lines indicates the absence of evidence for linear changes in an aspect of biodiversity after hurricane-induced disturbance.

2006). Disturbance-induced mortality can disrupt such patterns of nestedness, whether the effects are density dependent or independent (Figure 6), an interpretation consistent with observations after Hurricane Georges (no pre-hurricane data on nestedness exist for Hurricane Hugo). The subsequent increases in nestedness during secondary succession may reflect major microclimatic differences that arise as a result of these storms. Hurricanes produce many large openings in a forest, in which soil and air temperatures are high, evapotranspiration is high, and humidity is low compared to undisturbed forest (Denslow 1980; Fernández and Fetcher 1991). Moreover, the

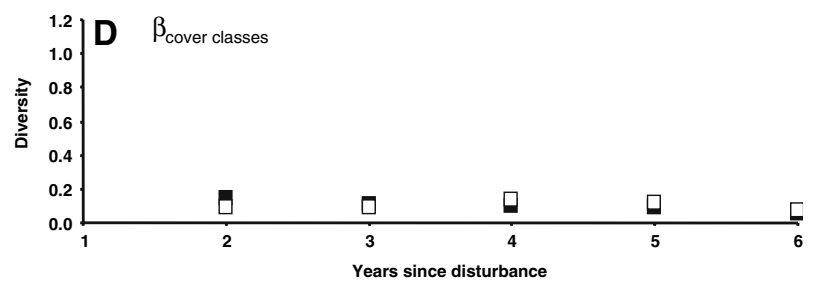

Figure 4. Long-term variation in spatial components of biodiversity, as measured by Shannon's Index, for terrestrial gastropods during the wet season on the Luquillo Forest Dynamics Plot, with a focus of trajectories of change after Hurricane Hugo (solid symbols and solid lines) and after Hurricane Georges (open symbols and dashed lines). Spatial scales (indicated by symbols) of species diversity include: A gamma $(\gamma)$, B alpha $(\alpha)$, C beta among sites $\left(\beta_{\text {sites }}\right)$, and $\mathbf{D}$ beta among cover classes $\left(\beta_{\mathrm{CC}}\right)$. When variation in an aspect of species diversity after Hurricane Hugo was indistinguishable from that after Hurricane Georges, a dashed and dotted line represents the trajectory of change. The absence of lines indicates the absence of evidence for linear changes in an aspect of biodiversity after hurricane-induced disturbance.

magnitude of difference in environmental conditions between gap and undisturbed forest increases with the size of the canopy opening (Lee 1978). These microclimatic characteristics affect gastropod assemblages because of species-specific responses to desiccation, an important cause of mortality for terrestrial gastropods (Solem 1984), especially eggs and juveniles. In addition, the large input of leaves 

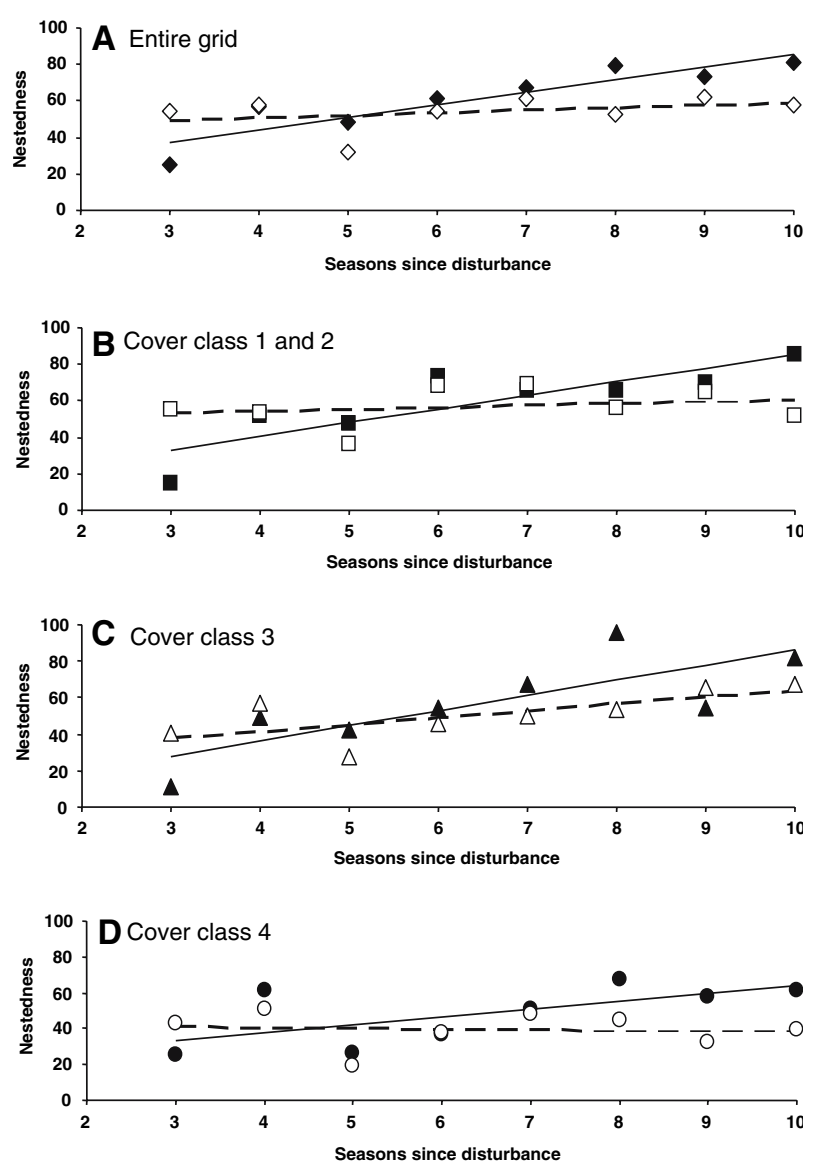

Figure 5. Long-term variation in nestedness of terrestrial gastropods during wet and dry seasons on the Luquillo Forest Dynamics Plot, with a focus on trajectories of change after Hurricane Hugo (solid diamonds and solid lines) and after Hurricane Georges (open diamonds and dashed lines). Spatial extents for analyses include: A the entire Luquillo Forest Dynamics Plot, B cover class 1 and 2, C cover class 3, and $\mathbf{D}$ cover class 4 .

and branches to the forest floor as a result of hurricane damage provides a major pulse in resources for bacteria and fungi, which are important food resources for some species of gastropod. Taken together, these factors likely caused differences in gastropod species composition among sites and over time. For example, at least one species, $N$. tridens, exploits resource pulses in small-scale disturbances (for example, tree fall gaps) in the LFDP, whereas another, Caracolus caracolla, is more abundant to undisturbed forest (Alvarez and Willig 1993).

The different responses following each hurricane may thus reflect a difference in the intensity and extent of hurricane damage. The initial levels of diversity and richness were somewhat higher and nestedness was lower after Hurricane Hugo compared to after Hurricane Georges because damage from the former occurred about 50 years after the last Hurricane at a time when canopy cover on the plot was relatively continuous. In contrast, Hurricane Georges struck only 9 years after Hurricane Hugo, at a time when canopy cover was incomplete. Moreover, the damage from Hurricane Hugo compared to Hurricane Georges was greater and produced a more heterogeneous environment. Nestedness increased over time more rapidly following Hurricane Hugo than following Hurricane Georges (Table 2), potentially reflecting differences in the attributes of disturbance associated with each storm. The different rate of responses following each hurricane may reflect the difference in the intensity and extent of hurricane damage (Brokaw and others). Because Hurricane Hugo produced more severe and a larger extent of canopy damage than did Hurricane Georges, the post disturbance rates of change in microclimatic characteristics (for example, temperature and humidity) and in the structure of vegetation arising from the growth of shrubs and pioneer trees were more rapid after Hurricane Hugo than Georges.

A previous analysis of nestedness of gastropod assemblages on the LFDP (Bloch and others 2007) revealed no difference between the trajectories of nestedness between the two hurricanes. Although that analysis comprised a larger sample size (that is, more estimates of nestedness over time), it included seasons following Hurricane Hugo for which no counterpart yet existed following Hurricane Georges (for example, the dry season of 1997 was 8 years after Hurricane Hugo, but there were no data for 2006, the eighth year following Hurricane Georges). Two factors may account for the different results. First, the strictly paired design in the current analysis provides better statistical power to detect a difference in slopes during the years for which paired data exist. Second, visual inspection of the data suggests that nestedness may have approached an asymptote approximately 6 years after Hurricane Hugo (Figure 1 in Bloch and others 2007). If so, differences in intensity between storms may affect the rate of change in nestedness following disturbance, but not the maximum attainable degree of nestedness.

The differences in nestedness among areas of historic land use after a hurricane apparently reflected pre-hurricane heterogeneity resulting from different intensities or types of human disturbance on the LFDP. More specifically, sites that experienced the least severe disturbance from agricultural practices in the past (that is, limited selective logging until the 1950s) consistently had gastropod assemblages that were less nested than did those 
Table 2. Results of Repeated Measures ANCOVAs Evaluating Effects of Disturbance by Hurricanes on Nestedness of Gastropod Assemblages at Two Spatial Scales

\begin{tabular}{|c|c|c|c|c|c|}
\hline \multicolumn{3}{|l|}{ Recognizing cover classes } & \multicolumn{3}{|l|}{ Ignoring cover classes } \\
\hline Source & $\mathrm{df}$ & $\mathbf{P}$ & Source & df & $\mathbf{P}$ \\
\hline Within subjects factors & & & Within subjects factors & & \\
\hline Hurricane & 1,20 & 0.005 & Hurricane & 1,6 & 0.071 \\
\hline Hurricane $\times$ time since disturbance & 1,20 & 0.001 & Hurricane $\times$ time since disturbance & 1,6 & 0.026 \\
\hline Hurricane $\times$ cover class & 2,20 & 0.679 & & & \\
\hline Between subjects factors & & & Between subjects factors & & \\
\hline Time since disturbance & 1,20 & $<0.001$ & Time since disturbance & 1,6 & 0.008 \\
\hline Cover class & 2,20 & 0.040 & & & \\
\hline
\end{tabular}

Spatial scales are within each of three areas characterized by different anthropogenic disturbance histories (reflected by historic canopy cover classes) and for the entire Luquillo Forest Dynamics Plot, irrespective of historic cover class. The factor hurricane identifies whether a sample came from the time period following Hurricane Hugo or Hurricane Georges. The covariate measures the number of semi-annual sampling seasons following disturbance. Significant results $(\alpha=0.10)$ appear in bold.

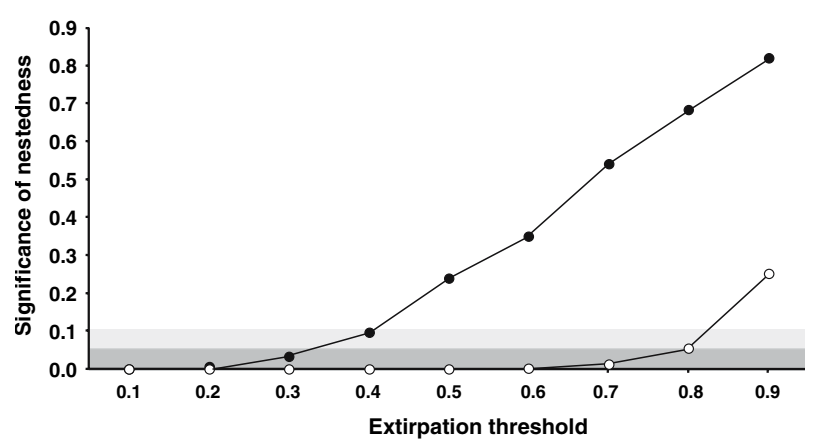

Figure 6. Results of simulations of the effect of disturbance-induced mortality on significance of nestedness of gastropods on the LFDP (see text for details). Closed circles indicate simulations in which extirpation was densityindependent. Open circles denote simulations in which extirpation was density-dependent. Shading denotes levels of significance (dark grey $P \leq 0.05$, light grey $0.05<P \leq 0.10)$. In general, nestedness decreases with increased mortality (extirpation threshold), and does so more quickly when mortality is density independent than when mortality is density dependent.

that were more severely disturbed, regardless of time since a hurricane (Bloch and others 2007). Historic land use influenced tree species composition and size prior to hurricane impact (Thompson and others 2002), which, in turn, affected degree of damage during the hurricanes, because tree species, size, and age influence susceptibility to hurricane damage (Zimmerman and others 1994; Brokaw 1998; Uriarte and others 2004). Thus, differences in the degree of nestedness of gastropod assemblages among areas of historic human land use were not unexpected to occur after hurricanes, although it was surprising that the degree of nestedness was lowest in the area historically subjected to limited and selective logging, regardless of time since disturbance. This portion of the LFDP (canopy cover class 4) contained several sites from which the two most abundant and widespread species, $C$. caracolla and $N$. tridens, were often absent, possibly because the complexity of vertical structure and the amount of decaying plant matter were low after the hurricanes relative to the other regions of the LFDP (Willig and others, unpublished data). Moreover, some infrequent gastropod species, such as Alcadia striata and especially Platysuccinea portoricensis, were more common at such sites, often occupying those devoid of the more widespread species. This pattern of species distribution resulted in lower nestedness as a consequence of a greater number of "holes" (that is, unexpected species absences) and "outliers" (unexpected species presences) in the portion of the LFPD that experienced the least intense disturbance by humans. Nevertheless, unlike the situation with patterns of biodiversity of terrestrial gastropods, heterogeneity generated by the history of natural and anthropogenic disturbance changed only the magnitude, rather than the trajectory, of nestedness with increasing spatial scale.

\section{Synthesis}

The snail assemblage on the LFDP may represent a metacommunity (Wilson 1992; Leibold and others 2004; Holyoak and others 2005) with a high degree of nestedness and connectivity among sites prior to hurricane disturbance, when canopy cover was extensive and environmental conditions at the level of the understory were more homogeneous in the forest. This may have been particularly true prior to Hurricane Hugo, as the forest had not experienced a hurricane of such intensity in decades. The immediate impact of the hurricane was to alter the abundance of species at some sites more 
than others and cause local extirpations, thereby decreasing the degree of nestedness on the LFDP. By creating extensive tree and branch falls, and removing massive quantities of living leaves from the canopy, hurricanes also modify environmental conditions (increased light, temperature, and carbon inputs; decreased humidity) to make them more stressful for terrestrial gastropods, especially in sites of severe disturbance. These environmental changes differentially affected local populations through fine-scale processes (Figure 1A) throughout post-hurricane secondary succession. At a broader scale, the reconfigured landscape of patches modified transfer processes among sites, especially the likelihood of dispersal of particular species among locations. Because movement by gastropods is costly in terms of water, activity is reduced by unfavorable microclimatic conditions (reviewed in Cook 2001). Consequently, dispersal rates across severely disturbed patches of habitat should be low. As such, species that are driven to local extinction may not rapidly be replaced via the rescue effect from subpopulations in other patches. These cross-scale interactions also altered local (site) and consequently regional (LFPD) speciesabundance distributions. As forest cover and vegetation structure regenerated over time, the microclimatological characteristics ameliorated from the perspective of gastropods. The improved environmental conditions for gastropods at local sites likely altered fine-scale processes resulting in decreased mortality, increased fecundity, and consequently higher density, as well as increased activity of individuals. These in turn resulted in increased selective pressures that favored dispersal into areas that were more severely modified by disturbance. Simultaneously, environmental homogeneity (with respect to a number of critical environmental conditions) and connectivity likely increased among sites, cumulatively enhancing the degree of nestedness in the assemblage. The rate of increase in nestedness depended on the particular hurricane (initial nestedness after Hurricane Georges was higher than Hugo in all land use areas), and increased at a slower rate after Hurricane Georges than after Hurricane Hugo. Because Hurricane Georges did not disrupt canopy structure to the same degree as did Hurricane Hugo, nestedness was less affected as an immediate consequence of the disturbance. The lesser input of leaves and branches to the forest floor from Hurricane Georges compared to Hurricane Hugo also provided smaller quantities of organic carbon for assimilation by microbial food sources, and induced only minor changes in understory plants during subsequent secondary succession. Thus the rate of increase in nestedness of gastropods was less after Hurricane Georges than after Hurricane Hugo. These consistent patterns in hurricane response, however, overlie differences due to heterogeneity in assemblages as a result of past land use. Thus, hurricanes alter fine-scale processes, and together with underlying environmental heterogeneity, explain why biodiversity measures did not scale easily from local to broader scales in the LFDP. This scaling phenomenon may be especially important when land-use history belies important environmental legacies.

This study demonstrated the need to characterize fine-scale, population and assemblage-level processes, as well as the need to determine broad-scale patterns of heterogeneity over an entire landscape that effect patch connectivity and transfer processes, so as to effectively understand and model the dynamics of biodiversity in a disturbance mediated, tropical ecosystem. In this study, underlying environmental heterogeneity was related to disturbances that arose from anthropogenic and natural causes. Because of increasing human demands on ecosystems and widespread alterations in natural disturbance regimes that arise as a consequence of global climate change, effective conservation planning depends on understanding the spatiotemporal dynamics of biodiversity, especially the complex effects of scale and cross-scale interactions.

\section{ACKNOWLEDGEMENTS}

This research was supported by grants BSR8811902, DEB 9411973, DEB 0080538, and DEB 0218039 from NSF to the Institute for Tropical Ecosystem Studies, University of Puerto Rico, and to the International Institute of Tropical Forestry, USDA Forest Service, as part of the Long-Term Ecological Research Program in the Luquillo Experimental Forest. The USDA Forest Service, US Department of Energy, the University of Puerto Rico, the Howard Hughes Medical Institute, Texas Tech University, and the University of Connecticut provided additional support. We are grateful to Steven J. Presley for rendering editorial assistance, as well as to two anonymous reviewers and Donald L. DeAngelis, for critical comments on an earlier version of the manuscript that enhanced clarity and conceptual development. Thomas O. Crist kindly made the program PARTITION available for use in estimating hierarchical spatial components of biodiversity. We thank the staff of El Verde Field Station, as well as our students and colleagues, too 
many to name individually, who assisted with field work on gastropods over the years. Finally, we thank Debra Peters for the invitation to contribute to the Special Feature, and for her insightful comments on earlier versions of the manuscript.

\section{REFERENCES}

Aide TM, Zimmerman JK, Pascarella J, Rivera L, Marcano-Vega H. 2000. Forest regeneration in a chronosequence of tropical abandoned pastures: implications for restoration ecology. Restoration Ecology 8:328-38.

Allen TFH, Hoekstra TW. 1993. Towards a unified ecology. New York: Columbia University Press.

Alvarez J, Willig MR. 1993. Effects of treefall gaps on the density of land snails in the Luquillo Experimental Forest of Puerto Rico. Biotropica 25:100-10.

Arrhenius O. 1921. Species and area. J Ecology 9:95-9.

Arrhenius O. 1923. Statistical investigations in the constitution of plant associations. Ecology 4:68-73.

Arrhenius O. 1923. On the relation between species and area-a reply. Ecology 4:90-91.

Azeria ET, Carlson A, Pärt T, Wiklund CG. 2006. Temporal dynamics and nestedness of an oceanic island bird fauna. Glob Ecol Biogeogr 15:328-38.

Bloch CP, Weiss L. 2002. Distribution and abundance of the whipspider Phrynus longipes (Arachnida: Amblypygi) in the Luquillo Experimental Forest, Puerto Rico: response to natural and anthropogenic disturbance. Carib J Sci 38:260-2.

Bloch CP, Willig MR. 2006. Context-dependence of long-term responses of terrestrial gastropod populations to large-scale disturbance. J Trop Ecol 22:111-22.

Bloch CP, Higgins CL, Willig MR. 2007. Effects of large-scale disturbance on metacommunity structure of terrestrial gastropods: temporal trends in nestedness. Oikos 116:395-406.

Brokaw NVL. 1998. Cecropia schreberiana in the Luquillo Mountains of Puerto Rico. Botan Rev 64:91-120.

Brokaw N, Zimmerman JK, Willig MR, Bloch CB, Camilo GR, Covich A, Crowl T, Fetcher N, Gannon MR, Haines B, Lodge DJ, Lugo A, Myster R, Pringle CM, Sharpe J, Scatena F, Schowalter T, Silver W, Thompson J, Vogt D, Vogt K, Waide $\mathrm{RB}$, Walker L, Woolbright L, Wunderle J, Zou X in litt. Response to disturbance. In Brokaw N, Crowl T, McDowell W, Lugo A, Scatena F, Waide RB, Willig MR, Eds. Disturbance, response, and tropical forest dynamics: long-term perspectives and implications. Oxford: Oxford University Press.

Brown S, Lugo AE, Silander S, Liegel L. 1983. Research history and opportunities in the Luquillo Experimental Forest. USDA Forest Service General Technical Report SO-44, Southern Forest Experiment Station, New Orleans, Louisiana, USA.

Chalcraft DR, Williams JW, Smith MD, Willig MR. 2004. Scale dependence in the relationship between species richness and productivity: the role of spatial and temporal turnover. Ecology 85:2701-7.

Chase JM, Leibold MA. 2002. Spatial scale dictates the productivity-biodiversity relationship. Nature 416:427-30.

Clements FE. 1916. Plant succession: an analysis of the development of vegetation. Washington: Carnegie Institution of Washington.

Cook A. 2001. Behavioural ecology: on doing the right thing, in the right place, at the right time. In: Barker GM, Ed. The biology of terrestrial molluscs. Wallingford: CAB International. pp 447-87.

Crist TO, Veech JA, Gering JC, Summerville KS. 2003. Partitioning species diversity across landscapes and regions: a hierarchical analysis of $\alpha, \beta$, and $\gamma$ diversity. Amer Natur 162:734-43.

Denslow JS. 1980. Patterns of plant species diversity during succession under different disturbance regimes. Oecol 46:18-21.

Diamond JM (1975) Assembly of species communities. In: Diamond JM, Ed. Ecology and evolution of communities. Cambridge: Harvard University Press. pp 342-444.

Ewel JJ, Whitmore JL. 1973. The ecological life zones of Puerto Rico and the United States Virgin Islands. Forest Service Research Papers ITF-18. International Institute of Tropical Forestry, Río Piedras, Puerto Rico.

Falk DA, Miller C, McKenzie D, Black AE. 2007. Cross-scale analysis of fire regimes. Ecosystems (this issue).

Frenández DS, Fetcher N. 1991. Changes in light availability following Hurricane Hugo in a subtropical montane forest in Puerto Rico. Biotropica 23:393-9.

García Montiel DC, Scatena FN. 1994. The effect of human activity on the structure and composition of a tropical forest in Puerto Rico. For Ecol Manage 63:57-78.

Garrison RW, Willig MR. 1996. Arboreal invertebrates. In: Waide RB, Reagan DP, Eds. The food web of a tropical rain forest. Chicago: University of Chicago Press. pp 183-245.

Gleason HA. 1926. The individualistic concept of the plant association. Bull Torrey Bot Club 53:7-26.

Goldenberg SB, Landsea CW, Mestas-Nunez AM, Gray WM. 2001. The recent increase in Atlantic hurricane activity: causes and implications. Science 293:474-9.

Gorresen PM, Willig MR, Strauss RE. 2005. Population and community-level responses of phyllostomid bats to landscape structure: the importance of scale. Ecol Appl 15:2126-36.

Grau HR, Aide TM, Zimmerman JK, Thomlinson JR, Helmer E, Zou X. 2003. The ecological consequences of socioeconomic and land-use changes in post agriculture Puerto Rico. BioScience 53:1159-68.

Gray JS, Ugland KI, Lambshead J. 2004a. On species accumulation and species-area curves. Glob Ecol Biogeogr 13:567-8.

Gray JS, Ugland KI, Lambshead J. 2004b. Species accumulation and species area curves-a comment on Scheiner 2003. Glob Ecol Biogeogr 13:473-6.

Higgins CL, Willig MR, Strauss RE. 2006. The role of stochastic processes in producing nested patterns of species distributions. Oikos 114:159-67.

Holling CS. 1992. Cross-scale morphology, geometry, and dynamics of ecosystems. Ecol Monogr 62:447-502.

Holyoak M, Leibold MA, Mouquet NM, Holt RD, Hoopes MF. 2005. Metacommunities: a framework for large-scale community ecology. In: Holyoak M, Leibold MA, Holt RD, Eds. Metacommunities: spatial dynamics and ecological communities. Chicago: University of Chicago Press. pp 1-31.

Hurlbert SH. 2003. Design and analysis: uncertain intent, uncertain result. Ecology 84:810-2.

Huston MA. 1994. Biological diversity: the coexistence of species in changing landscapes. Cambridge: Cambridge University Press.

Huston MA. 1997. Hidden treatments in ecological experiments: re-evaluating the ecosystem function of biodiversity. Oecol 110:449-60. 
Kaufman DM, Kaufman GA, Kaufman DW. 2000. Faunal structure of small mammals in tallgrass prairie: an evaluation of richness and spatiotemporal nestedness. Fort Hays Stud Spec Issue 1:47-70.

Landsea CW, Pielke RA Jr, Mestas-Núñez AM, Knaff JA. 1999. Atlantic basin hurricanes: indices of climatic changes. Clim Change 42:89-129.

Lawton JH. 1994. What do species do in ecosystems? Oikos 71:174-83.

Lawton JH, Naeem S, Thompson LJ, Hector A, Crawley MJ. 1998. Biodiversity and ecosystem function: getting the Ecotron experiment in its correct context. Func Ecol 12:848-52.

Lee R. 1978. Forest microclimatology. New York: Columbia University Press

Leibold MA, Holyoak M, Mouquet N, Amarasekare P, Chase JM, Hoopes MF, Holt RD, Shurin JB, Law R, Tilman D, Loreau M, González A. 2004. The metacommunity concept: a framework for multi-scale ecology. Ecol Lett 7:01-613.

Leibold MA, Mikkelson GM. 2002. Coherence, species turnover, and boundary clumping: elements of meta-community structure. Oikos 97:237-50.

Levin SA. 1992. The problem of pattern and scale in ecology. Ecology 73:1943-67.

López T del M, Aide TM, Thomlinson JR (2001) Urban expansion and the loss of prime agricultural lands in Puerto Rico Ambio 30:49-54.

Lyons SK, Willig MR. 1999. A hemispheric assessment of scaledependence in latitudinal gradients of species richness. Ecology 80:2483-91.

Lyons SK, Willig MR. 2002. Species richness, latitude, and scalesensitivity. Ecology 83:47-58.

Magurran AE. 1988. Ecological diversity and its measurement. Princeton: Princeton University Press.

Mason CF. 1970. Snail populations, beech litter production, and the role of snails in litter decomposition. Oecol 5:215-39.

Mittelbach GG, Steiner CF, Gross KL, Reynolds HL, Scheiner SM, Waide RB, Willig MR, Dodson SI. 2001. The relationship between species richness and productivity depends on scale. Ecology 82:2381-96.

Moran MD. 2003. Arguments for rejecting the sequential Bonferroni in ecological studies. Oikos 100:403-5.

Myers N (2001) Hotspots. In: Levin SA, Ed. Encyclopedia of biodiversity Vol 3. San Diego: Academic Press. pp 371-81.

Myers N, Mittermeier RA, Mittermeier CG, da Fonseca GAB, Kent J. 2000. Biodiversity hotspots for conservation priorities. Nature 403:853-8.

Norton J, Lewis JW, Rollinson D. 2004. Temporal and spatial patterns of nestedness in eel macroparasite communities. Parasitol 129:203-11.

Patterson BD, Atmar W. 1986. Nested subsets and the structure of insular mammalian faunas and archipelagos. Biol J Linn Soc 28:65-82.

Peters DPC, Havstad KM. 2006. Nonlinear dynamics in arid and semi-arid systems: interactions among drivers and processes across scales. J Arid Envion 65:196-206.

Peters DPC, Bestelmeyer BT, Turner MG. 2006. Cross-scale interactions and changing pattern-process relationships: consequences for system dynamics. Ecosystems (this issue).

Peterson GD, Allen CR, Holling CS. 1998. Ecological resilience, biodiversity and scale. Ecosystems 1:6-18.
Pickett STA, Wu J, Cadenas ML (1999) Patch dynamics and the ecology of disturbed ground: a framework for synthesis. In: Walker LR, Ed. Ecosystems of the world 16: ecosystems of disturbed ground. Amsterdam: Elsevier. pp 707-22.

Purchon RD. 1977. The biology of the Mollusca. New York: Pergamon.

Rice WR. 1989. Analyzing tables of statistical results. Evolution 43:223-5.

Scatena FN, Larsen MC. 1991. Physical aspects of Hurricane Hugo in Puerto Rico. Biotropica 23:317-23.

Scheiner SM. 2003. Six types of species-area curves. Glob Ecol Biogeogr 12:441-7.

Scheiner SM. 2004. A mélange of curves-further dialogue about species-area relationships. Glob Ecol Biogeogr 13:47984.

Scheiner SM, Cox SB, Willig MR, Mittelbach GG, Osenberg CW, Kaspari M. 2000. Species richness: scale effects and speciesarea curves. Evol Ecol Res 2:791-802.

Secrest MF, Willig MR, Lind LL. 1996. The legacy of disturbance on habitat associations of terrestrial snails in the Luquillo Experimental Forest, Puerto Rico. Biotropica 28:502-14.

Sfenthourakis S, Gioka S, Tzanatos E. 2004. From sampling stations to archipelagos: investigating aspects of the assemblage of insular biota. Glob Ecol Biogeogr 13:23-35.

Simberloff D. 1983. Competition theory, hypothesis testing, and other community ecological buzzwords. Amer Natur 122:62635.

Solem A (1984) A world model of land snail diversity and abundance. In: Solem A, van Bruggen AC, Eds. World-wide snails: biogeographic studies on non-marine Mollusca. Leiden: EJ Brill. pp 6-22.

SPSS, Inc. 1990a. SPSS base system user's guide. Chicago: SPSS Inc.

SPSS, Inc. 1990b. SPSS reference guide. Chicago: SPSS Inc.

Srivastava DS. 2005. Do local processes scale to global patterns? The role of drought and the species pool in determining treehole insect diversity. Oecol 145:204-14.

Stevens RD, Willig MR. 2002. Geographical ecology at the community level: perspectives on the diversity of New World bats. Ecology 83:545-60.

Summerville KS, Veech JA, Crist TO. 2002. Does variation in patch use among butterfly species contribute to nestedness at fine spatial scales?. Oikos 97:195-204.

Tanner EVJ, Kapos V, Healey JR. 1991. Hurricane effects of forest ecosystems in the Caribbean. Biotropica 23:513-21.

Thompson J, Brokaw N, Zimmerman JK, Waide RB, Everham EM III, Lodge DJ, Taylor CM, García-Montiel D, Fluet M. 2002. Landuse history, environment, and tree composition in a tropical forest. Ecol Appl 12:1344-63.

Thompson J, Brokaw N, Zimmerman JK, Waide RB, Everham EM III, Schaefer DA. 2004. Luquillo Forest Dynamics Plot. In: Losos E, Leigh EG, Eds. Tropical forest diversity and dynamism: results from a long-term tropical forest network. Chicago: University of Chicago Press. pp 540-50.

Uriarte M, Canham CD, Thompson J, Zimmerman JK. 2004. A neighborhood analysis of tree growth and survival in a hurricane-driven tropical forest. Ecol Monogr 74:591-614.

von Humbolt FHA. 1807. 1959 Essai sur la geographie des plantes (Sherborn Fund facsimilie, no. 1). London (UK): Society for the Bibliography of Natural History. 
Waide RB, Lugo AE (1992) A research perspective on disturbance and recovery of a tropical montane forest. In: Goldammer J, Ed. Tropical forest in transition: ecology of natural and anthropogenic disturbance processes. Basal: BerkhauserVerlag. pp 31-7.

Waide RB, Reagan DP. 1996. The rain forest setting. In: Reagan DP, Waide RB, Eds. The food web of a tropical rain forest. Chicago: University of Chicago Press. pp 1-16.

Waide RB, Willig MR, Mittelbach G, Steiner C, Gough L, Dodson SI, Juday GP, Parmenter R. 1999. The relationship between primary productivity and species richness. Ann Rev Ecol Syst 30:257-300.

Walker LR, Lodge DJ, Brokaw NVL, Waide RB. 1991. Ecosystem, plant and animal responses to hurricanes in the Caribbean. Biotropica 23:313-521.

Walker LR, Silver WL, Willig MR, Zimmerman JK. 1996. Long term responses of Caribbean ecosystems to disturbance. Biotropica 28:414-614.

Wardle DA, Bonner KI, Nicholson KS. 1997. Biodiversity and plant litter: experimental evidence which does not support the view that enhanced species richness improves ecosystem function. Oikos 79:247-58.

Webster PJ, Holland GJ, Curry JA, Chang H-R. 2005. Changes in tropical cyclone number, duration, and intensity in a warming environment. Science 309:1844-6.

Whittaker RJ, Willis KJ, Field R. 2001. Scale and species richness: towards a general, hierarchical theory of species diversity. J Biogeogr 28:453-70.

Willig MR, Bloch CP. 2006. Latitudinal gradients of species richness: a test of the geographic area hypothesis. Oikos 112:163-73.

Willig MR, Camilo GR. 1991. The effect of Hurricane Hugo on six invertebrate species in the Luquillo Experimental Forest of Puerto Rico. Biotropica 23:455-61.
Willig MR, Walker LR (1999) Disturbance in terrestrial ecosystems: salient themes, synthesis, and future directions. In: Walker LR, Ed. Ecosystems of disturbed ground. Amsterdam: Elsevier. pp 747-67.

Willig MR, Kaufman DM, Stevens RD. 2003. Latitudinal gradients of biodiversity: pattern, process, scale, and synthesis. Ann Rev Ecol Evol Syst 34:273-309.

Willig MR, Moorhead DL, Cox SB, Zak JC. 1996. Functional diversity of soil bacterial communities in the tabonuco forest: interaction of anthropogenic and natural disturbance. Biotropica 28:471-83.

Willig MR, Secrest MF, Cox SB, Camilo GR, Cary JF, Alvarez J, Gannon MR. 1998. Long-term monitoring of snails in the Luquillo Experimental Forest of Puerto Rico: heterogeneity, scale, disturbance, and recovery. In: Dallmeier F, Comisky J, Eds. Forest biodiversity in North, Central, and South America and the Caribbean: research and monitoring. Carnforth: UNESCO and The Parthenon Press. pp 293-322.

Wilson DS. 1992. Complex interactions in metacommunities, with implications for biodiversity and higher levels of selection. Ecology 73:1984-2000.

Woods CA, Ed. (1989) Biogeography of the West Indies: past, present, and future. Gainesville: Sandhill Crane Press.

Woods CA, Sergile FE, Eds. 2001. Biogeography of the West Indies: patterns and perspectives. Boca Raton: CRC Press.

Wright DH, Reeves JH. 1992. On the meaning and measurement of nestedness of species assemblages. Oecologia 92:416-28.

Wright DH, Patterson BD, Mikkelson GM, Cutler A, Atmar W. 1998. A comparative analysis of nested subset patterns of species composition. Oecologia 113:1-20.

Zimmerman JK, Everham EM III, Waide RB, Lodge DJ, Taylor CM, Brokaw NVL. 1994. Responses of tree species to hurricane winds in subtropical wet forest in Puerto Rico: implications for tropical tree life histories. J Ecol 82:911-22. 